\title{
INSCRIÇÕES EM MOEDAS GREGAS: O PERÍODO ARCAICO E CLÁSSICO
}

\author{
LILIAN DE ANGELO LAKY* \\ Museu de Arqueologia e Etnologia \\ Universidade de São Paulo
}

\begin{abstract}
RESUMO: Este artigo busca apresentar o estudo das inscrições nas moedas a partir das variedades encontradas nos tipos monetários de póleis do mundo grego pertencentes ao período arcaico e clássico. Discute-se a tradução e a interpretação das legendas, em relação à origem e à função da moeda como objeto de afirmação política e de identidade da pólis.
\end{abstract}

PALAVRAS-CHAVE: pólis; epigrafia; numismática; período arcaico; período clássico.

\section{Introdução}

A moeda grega faz parte do conjunto de inovações operadas nas diversas instâncias do mundo grego em época arcaica (séculos VIII-VI a.C.). A sua invenção no século VII a.C. foi logo apropriada pela pólis grega no momento em que ela começava a organizar seu espaço físico, seu sistema político e, por conseguinte, a afirmar-se politicamente. Os antigos gregos foram os primeiros a utilizar a moeda em larga-escala e este processo remonta ao século VI a.C., quando do Oriente ao Ocidente grego a cunhagem de moedas se consolidou como uma instituição da pólis. Este foi o mesmo momento em que os templos desenvolveram o ideal de monumentalidade e proporção, tornando-se emblemas de prestígio e poder das póleis. Assim, é neste contexto que a expansão rápida da cunhagem produziu a primeira sociedade monetarizada (Seaford, 2003, p. xi) ${ }^{1}$.

* Mestranda em Arqueologia Clássica do Museu de Arqueologia e Etnologia (MAE / USP). Membro ativo do Laboratório de Estudos da Cidade Antiga (LABECA / MAE / USP) www.mae.usp.br/labeca/

1 Essa importante mudança no período foi estudada por Richard Seaford² (2003, p. xi), professor de literatura grega na Universidade de Exeter, Inglaterra. Após analisar minu- 
Atualmente se aceita que a moeda foi criada na Ásia Menor e posteriormente adotada e difundida entre as póleis gregas do continente. De fato as moedas mais antigas, conhecidas hoje, foram encontradas em um depósito nas fundações do templo arcaico de Ártemis em Éfeso durante as escavações do Museu Britânico entre os anos de 1904 e 1905. As noventa e três moedas feitas de elétron (uma liga natural de ouro e prata) são datadas de 630 a.C. Esta descoberta vai ao encontro do registro de Heródoto $(\mathrm{I}, 94)^{2}$, quem diz que foram os lídios os primeiros a cunhar moedas de ouro e prata.

A adoção da moeda no mundo grego transcorreu algum tempo após sua criação na Ásia Menor. A tradição também registra que foi Fídon, tirano de Argos, que teria cunhado em Egina pela primeira vez a moeda de prata $^{3}$. Fídon, ativo na primeira metade do século VII a.C. foi deposto pelos tiranos de Corinto e Sicione entre 660-650 a.C. A documentação escrita também diz que Fídon teria recolhido os espetos de ferro e com eles feito uma dedicação no Heraion de Argos e então cunhado as moedas de prata 4 .

Nas escavações do Heraion de Argos no século XIX os arqueólogos encontraram um maço de espetos de ferro e uma barra também de ferro, ambos dedicados à divindade. Além disso, as moedas de Egina são justamente aquelas que os estudiosos obtiveram as datações mais antigas (c.570 a.C.) (Florenzano, 2001, p. 202).

Em linhas gerais, este é o quadro tradicionalmente proposto e aceito para a origem, adoção e difusão da moeda na Grécia.

\section{Epigrafia numismática grega}

É certo que os gregos antigos já haviam utilizado a escrita em materiais perecíveis como o couro ou a madeira em uma ou duas gerações antes das inscrições mais antigas encontradas na cerâmica, datadas de aproximadamente 730 a.C., provenientes da Eubéia (Cook, 1987, p. 9).

ciosamente o pensamento pré-socrático e as tragédias, concluiu que a monetarização da pólis grega a partir do século VI a.C. contribuiu para uma transformação radical no pensamento grego até o século $\mathrm{V}$ a.C.

2 "Os lídios foram os primeiros entre os homens, até onde vai o nosso conhecimento, a cunhar e usar moedas de ouro e prata, e também foram os primeiros a vender mercadorias a varejo". Heródoto, I, 94; meados do século V a.C (apud Florenzano, 2001, p. 209).

3 Encontramos o trecho em Éforo, frag.176; século IV a.C.: “...e Éforo diz que a moeda de prata foi cunhada pela primeira vez em Egina, por Fídon” (apud Florenzano, 2001, p. 209).

4 “...e Fídon de Argos foi o primeiro a cunhar a moeda em Egina; depois de ter emitido moeda, ele recolheu os espetos e os dedicou a Hera de Argos”. Órion, Etymologicum, s.v. óbelos; século V d.C. (apud Florenzano, 2001, p. 209). 
Mas no documento monetário, as primeiras inscrições aparecem em 630 a.C. nas moedas de életron do depósito do Artemísion de Éfeso. Encontradas pelos arqueólogos ingleses em meio a grande variedade de jóias, artefatos de âmbar e pequeníssimas estatuetas de marfim, estas moedas possuem pesos variados, algumas sem qualquer figuração ou apenas com marcas de estrias ou punções, e outras com carimbo de figuras (leão, pata de leão, galos, bodes, besouro, foca, grifo, veado, touro, cabeça masculina) em uma das faces e punções na outra (Florenzano, 2001, p. 203). As inscrições que aparecem em algumas delas indicam que foram emitidas por indivíduos e não por algum dos Estados da Ásia Menor, ainda que esta seja uma hipótese possível no tocante às peças que não possuem inscrição (Florenzano, 2001, p. 204). Nesse sentido, conforme Colin Kraay (Kraay, 1976, p. 6), a inscrição mais antiga das peças de elétron diz: Eu sou o [sema] (insígnia) de Fanes (ФANE $\Sigma$ EIMI).

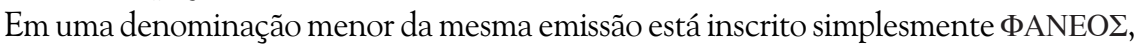
que propicia um protótipo para todos os subseqüentes étnicos no genitivo.

A difusão da cunhagem de moedas pelo mundo grego não significou uma difusão concomitante das inscrições. Com efeito, os manuais de numismática geral costumam dizer que a maioria das moedas traz legendas nas duas faces. As legendas são todos os tipos de inscrições que figuram nas moedas (Gauthier, 1975, p. 165).

A inscrição pode ter sido colocada no campo da moeda, sozinha ou não, mas com mais freqüência ela se encontra na orla ou no exergo. No primeiro caso ela pode estar tanto dirigida para a esquerda quanto para a direita, subindo ou descendo, a partir de um ponto qualquer da circunferência, numa única linha ou em várias linhas concêntricas ou esparsas. A base das letras é voltada para a orla ou para o centro da peça (Frère, 1984, p. 64).

As peças desprovidas de inscrições denominam-se anepígrafas (Frère, 1984, p. 64). Na Grécia as moedas mais antigas eram anepígrafas e muitas delas permaneceram assim até o fim de suas emissões. Conforme explica Hansen (Hansen, 2005, p. 147), muitas moedas sem inscrições pertencem ao período arcaico e início do período clássico e podem ser inseridas nas comunidades que, no período clássico tardio, continuam a bater moedas com os mesmos tipos, porém usando legendas.

Segundo nos ensina L. Lacroix (Lacroix, 1975, p. 155), algumas dessas moedas sem inscrições eram chamadas de tipos falantes, pois a imagem ${ }^{5}$ escolhida para figurar na moeda indica o nome da pólis. Podemos citar o caso da rosa (rodós),

5 As moedas gregas possuem um significado distinto dentro da arte grega. Diferente das esculturas das métopas e frisos dos templos ou das pinturas em vasos, de significado narrativo, as imagens representadas nas moedas possuíam uma função emblemática, portanto alegórica e simbólica. 
que foi a imagem escolhida pela ilha de Rodes, o aipo (selinon) escolhido como motivo pela pólis de Selinonte na Sicília. De um modo geral, as imagens de divindades e de seus atributos, os heróis locais, os produtos agrícolas e os motivos de significado não conhecido, compõem o leque dos tipos de imagens observáveis na iconografia monetária grega.

A função mais comum das inscrições nas moedas era informar o nome do povo ou da autoridade que a emitiu. A partir do final do século VI a.C. na Sicília e em Atenas, do final do século $\mathrm{V}$ a.C. em Tasos e após o século IV a.C. nas póleis jônicas da Ásia Menor, os étnicos começaram a ser utilizados nas moedas para designar a autoridade emissora (Gauthier, 1975, p. 165). Os étnicos foram bem definidos no An Inventory of Archaic and Classical Greek Poleis (2005). Desde que a pólis no sentido de Estado era uma comunidade de cidadãos ou uma região, o caminho comum para nomear a pólis era usar o nominativo plural de uma forma adjetiva do seu nome, como o nome oficial da própria comunidade, e usar o toponímio como o nome de seu centro urbano. $\mathrm{O}$ étnico, portanto, era derivado ou relacionado ao toponímio que denota a pólis. $\mathrm{O}$ uso do étnico testemunha a subdivisão política do mundo grego em póleis e a comunicação constante entre cidadãos de diferentes póleis (Hansen, Nielsen, 2005, p. 58 e 62). É o que a análise da epigrafia monetária também sugere.

\section{Os tipos de legendas}

Os especialistas definiram quatro variedades principais de inscrições, de acordo com seus respectivos significados, as agrupando em tipos repetidos de legendas: a-) os étnicos e os toponímios; b-) os nomes de indivíduos (de oficiais ou de gravadores); c-) o nome de um deus ou herói; d-) os símbolos indicando denominação.

\section{A-) Os étnicos e os toponímios}

Os étnicos mais antigos eram abreviados ${ }^{6}$, mas no final do século VI a.C. o número de emissões ativas requeriu uma abreviação de três ou quatro letras para

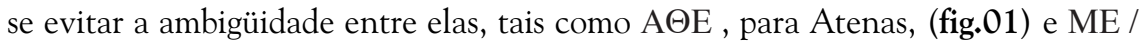
TA, para Metaponto, (fig.02) (Kraay, 1976, p. 5).

6 As abreviações são freqüentes quando o espaço no campo da moeda é exíguo (FRÈRE, 1984, 65). 

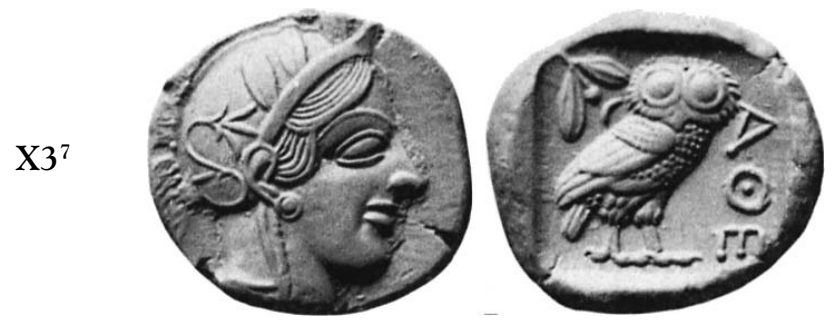

(fig.01)
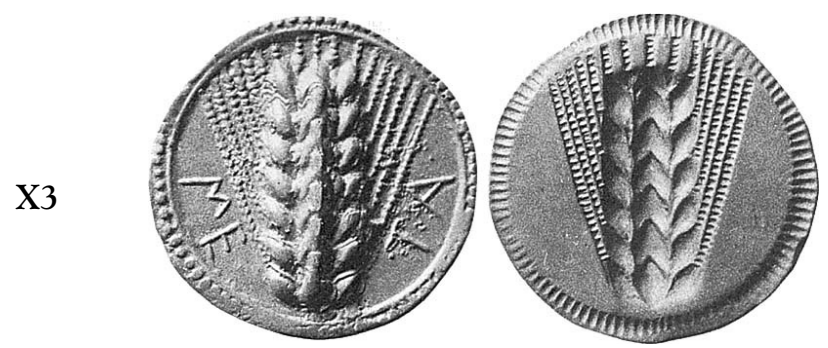

(fig.02)

O uso dos étnicos no genitivo plural refere-se à comunidade responsável pela emissão. Podemos citar os exemplares monetários de Siracusa do século V

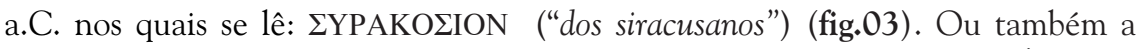
inscrição AKPAГANTIN $\Omega N$ (“dos acragantinos”) das moedas de Ákragas (Agrigento).
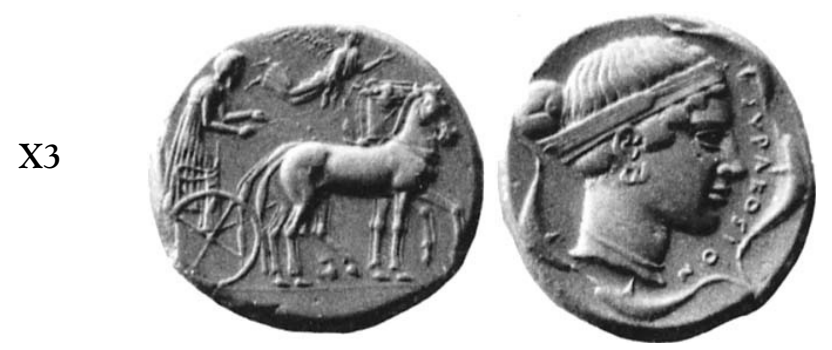

(fig.03)

De acordo com L. Lacroix (Lacroix, 1975, p. 167) há inscrições no genitivo ou no nominativo singular que não remetem ao nome da pólis, mas ao nome da

7 Esta notação se refere à ampliação da moeda por três vezes. 
divindade epônima da cidade. É o caso da legenda AKPAГ / ANTO $\Sigma$, "de Ákragas" (nome do rio da cidade) (fig.04), no genitivo singular, ou TAPA $\Sigma$ (nome do herói fundador de Tarento) no nominativo singular (fig.05).
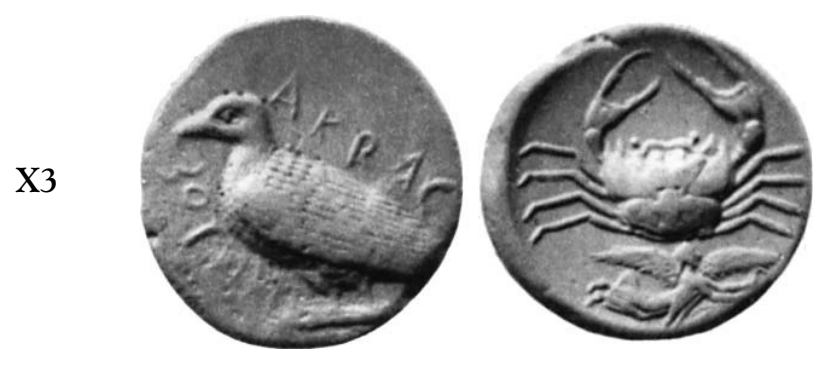

(fig.04)
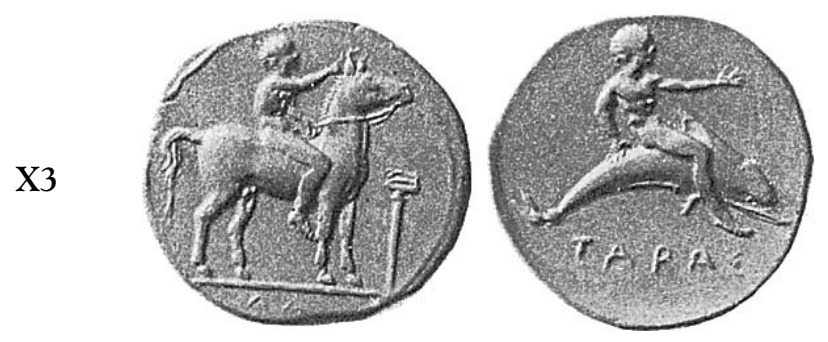

(fig.05)

$\mathrm{Na}$ forma do nominativo neutro singular encontramos inscrições que testemunham a formação de ligas ou confederações, como é o caso das emissões da Liga Arcádia de c. 490 a.C.: APKA / $\triangle \mathrm{IKON}$ (“dos arcádios”) (fig.06). O neutro singular também foi utilizado nas cunhagens de Élis para o santuário de Olímpia na primeira emissão de moedas em c. 470 a.C. A inscrição O $\Lambda$ IMПIKON pode ser lida como "dos olímpicos" (fig.07).
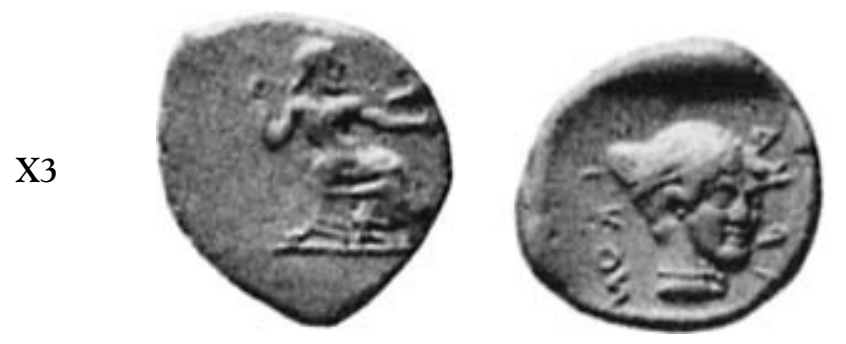

(fig.06) 


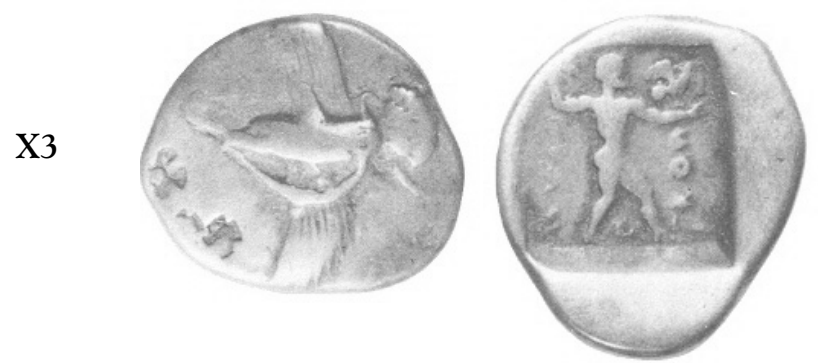

(fig.07)

\section{B-) Os nomes de indivíduos}

Embora se tornem mais comuns no século IV a.C., as primeiras inscrições com nomes de indivíduos (oficiais ou magistrados, gravadores e líderes) aparecem em moedas a partir do século V a.C. De Abdera, na Trácia, conhecemos as legendas mais antigas que se referem ao nome de um magistrado. Nas emissões, a palavra ЕПI ("no período de função de...") pode vir acompanhada do nome do magistrado no nominativo singular ou no genitivo, como é o caso do exemplar em questão: ЕП / HРО $\Delta \mathrm{OTO}$ ("no período de função de H[e]ródoto") (fig.08). Provavelmente, este é simplesmente um sistema de registro baseado no nome do principal magistrado local, que não era necessariamente o responsável formal pela cunhagem (Kraay, 1976, p. 7).
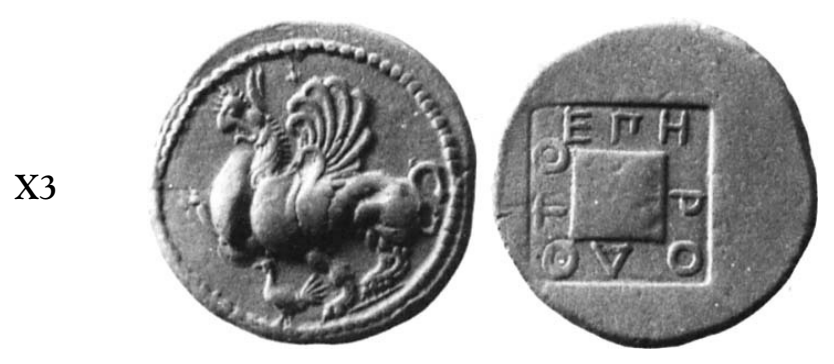

(fig.08)

Nos estudos de numismática grega são famosas as moedas de Siracusa do século $\mathrm{V}$ a.C, que foram assinadas pelos artistas que gravaram os seus cunhos ${ }^{8}$. Durante este período três mestres gravadores estiveram ativos no argyrokopeîon da pólis. Um deles era chamado Eukleides (em dialeto dórico, Eukleidas) e foi

8 O cunho é uma peça metálica de dureza superior a do metal monetário gravada com desenho em incuso que deseja imprimir na moeda (Marques, 1982, p. 68). 
responsável pelos desenhos de moedas siracusanas a partir de 440 a.C. (Rizzo,

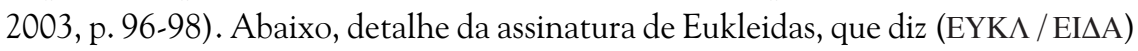
(fig.09):

X3

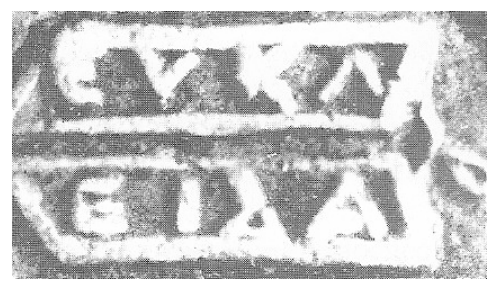

(fig.09)

A partir de finais do século IV a.C., à medida que o poderio macedônio se consolidava no Mediterrâneo, e que a autoridade emissora de moedas deixava de ser a pólis passando a ser o monarca, nomes pessoais começavam também a aparecer nas moedas. É o caso de Filipe II, da Macedônia, que no século IV a.C. realizou emissões em prata em seu nome ФІ ІІП / ППО [...] (“de Felipe”) (fig.10).
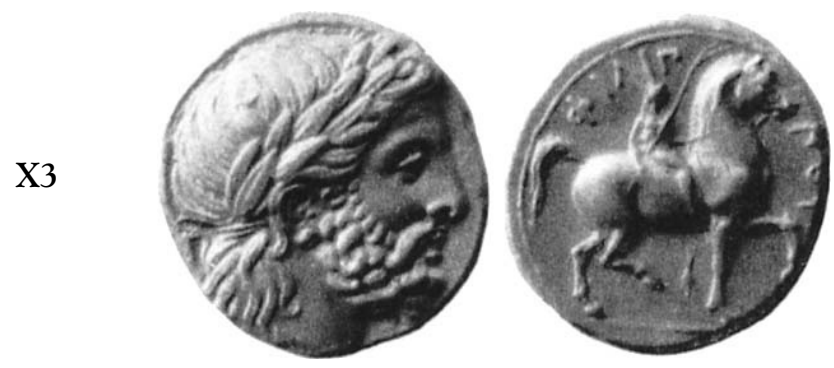

(fig.10)

\section{C-) Nomes de deuses e heróis}

Algumas moedas gregas possuem nomes de deuses, inscritos no nominativo, junto à imagem da divindade em questão. Em 345 a.C., quando Timoleonte pôs fim ao período de tirania restabelecendo o período de democracia em várias póleis da Sicília, Siracusa emitiu moedas com a imagem da cabeça de Zeus Eleutherios (Libertador). No anverso do exemplar, ao redor do desenho da cabeça do deus,

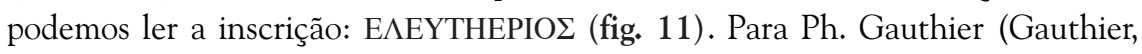
1975, p. 170), o nome da divindade no nominativo ("eu sou o deus") serve para precisar a sua imagem, que muitas vezes é suscetível de ser confundida com outras representações. Mas também a presença da inscrição do nome da divindade, 
associada à sua representação, pode indicar, simplesmente, que esta divindade tem um lugar eminente na vida desta pólis (Gauthier, 1975, p. 173).

X3
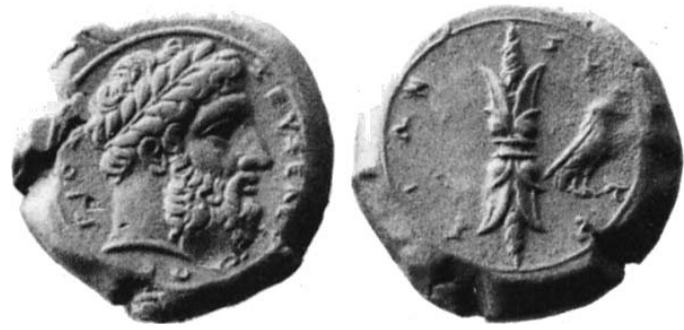

(fig.11)

Sobre as legendas que se referem ao nome de heróis, lembramos daquela de Taras (fig.05) mencionada anteriormente. A inscrição menciona o herói epônimo fundador da pólis de Taras (Tarento). Apesar de não possuir a imagem da divindade associada à legenda, é certo que o exemplar de Ácragas (fig.04) também se refere à divindade fluvial epônima da pólis (Gauthier, 1975, p. 167).

\section{D-) Símbolos indicando a denominação}

A inclusão de sinais identificadores da denominação - por meio de inscrições sobre a superfície da moeda - é rara na Grécia. Geralmente, as inscrições mais comuns estão resumidas a algumas letras esparsas dentro do campo da moeda. Nas moedas de Corinto o hemióbolo, o trihemióbolo e o dióbolo estão marcados, respectivamente, com as letras H, TPIH e $\Delta \mathrm{IO}$ (ou $\Delta$ ). No sul da Itália, o $O$ e o $O O$ são usados ocasionalmente para indicar o óbolo e o dióbolo. Na mesma região, na pólis de Posidônia, o trióbolo é indicado por III. Diante destes exemplos, podemos dizer que a marca da denominação variava de acordo com a região e / ou a pólis.

O caso mais conhecido, em que o nome da denominação é inscrito inteiramente na moeda, é o do óbolo de Metaponto datado do século IV a.C. no qual se lê a inscrição: [OB]O $\Lambda \mathrm{O} \Sigma$ (fig.12) (Kraay, 1976, p. 7-8; Hansen, 2005, p. 145).
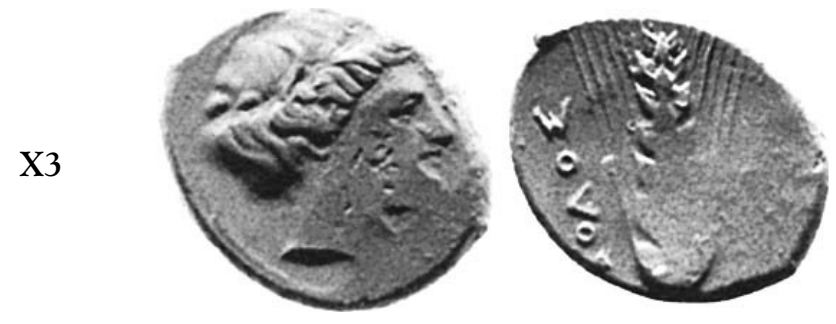

(fig. 12) 


\section{Conclusão}

A moeda grega representa o grau de organização e autonomia política da pólis. Foi um meio de afirmar sua existência e seu direito à soberania. Recentemente isso foi reafirmado pelo Copenhagen Polis Centre da Dinamarca na construção do primeiro inventário já realizado sobre as 1.498 póleis que existiram no mundo grego (Hansen; Nielsen, 2005, p. 3). A existência do documento monetário foi considerada como uma das evidências para o status de pólis, quando se buscava discernir a pólis ${ }^{9}$ do ethnos ${ }^{10}$.

Este pequeno objeto - a moeda - feito para circular por lugares próximos ou longínquos foi concebido para transmitir determinada informação sobre o local responsável pela sua fabricação. A mensagem poderia ser não-verbal, se a moeda portasse somente um conjunto de imagens gravadas. Mas, as inscrições identificavam com precisão a sua origem.

Em suma, como bem definiu o numismata francês Philippe Gauthier (Gauthier, 1975, p. 169):

As moedas são "monumentos políticos", que atestam a existência de um Estado independente. A legenda "moeda de..." - da mesma maneira que as fórmulas estabelecidas em um decreto ou em um tratado - contribui para atestar a autenticidade de um documento oficial, e também um valor político. Poderíamos dizer que a legenda tem menos o obj'etivo de identificar a moeda do que autenticá-la (a legenda contribui assim como os tipos para exprimir o valor político da moeda).

9 De acordo com o inventário, a antiga pólis grega consistiu em um centro nucleado, chamado de pólis no sentido urbano, e um território ao redor, chamado de chora ou ge (Hansen; Nielsen, 2005, p. 4).

Pólis é um conceito antigo e reflete a compreensão dos gregos de sua organização política e social, ao passo que cidade-estado é um conceito heurístico moderno inventado por historiadores para descrever não apenas as póleis gregas, mas também um número de outras cidades-estado no México, na Indonésia, na Irlanda, no Quênia e na Tanzânia (ibidem, p. 3).

10 Entre a pólis e o mundo grego como um todo existiu um tipo de unidade intermediária chamada ethnos (um grupo étnico associado a uma região específica) (ibidem, p. 4). 


\section{Descrição e proveniência das imagens}

Fig.01: Atenas; anv. cabeça de Atena com elmo; rev. coruja e galho de folhas de oliveira; 500-400 a.C.; tetradracma de prata. ID: SNGuk_0102_0197.

Fig.02: Metaponto; anv. e rev. espiga de trigo; c.550 a.C., estater de prata. ID: SNGuk_0300_0366. Fig. 03: Siracusa; anv. quadriga à direita e Nike; rev. cabeça feminina à direita e golfinhos ao redor; século $\mathrm{V}$ a.C.; tetradracma de prata. ID: SNGuk_0101b0007. Fig. 04: Agrigento; anv. águia à esquerda; rev. caranguejo e Nike; 475-450 a.C.; tetradracma de prata. ID: SNGuk_0102_0045. Fig.05: Taranto; anv. cavaleiro à direita; rev. homem sobre golfinho; $460-400$ a.C.; estater de prata. ID: SNGuk_0300_0151. Fig. 06: Liga Arcádia; anv. Zeus sentado no trono à direita segurando o cetro com a mão esquerda e o cetro com a direita; rev. Ártemis; 490 a.C.; 3 obeloi. ID: SNGuk_0102_0214. Fig.07: Élis; anv. Águia voando à esquerda e carregando uma serpente no bico; rev. Zeus nu em pé à direita atirando um raio com a mão d. e segurando no braço e. a águia pronta para voar; 470-450 a.C.; estater de prata. Kraay: 325. Fig. 08: Abdera; anv. Grifo sentado, abaixo galo; rev. legenda dentro de um quadrado; tetradracma de prata. ID: SNGuk_0101a0098. Fig.09: Siracusa (detalhe de inscrição em moeda); anv. quadriga; rev. Cabeça de Aretusa; 430-420 a.C.; tetradracma de prata. Rizzo, fig.59. Fig. 10: Macedônia (Felipe II); anv. cabeça laureada de Zeus à direita; rev. Jovem cavaleiro à direita; c.356 a.C.; tetradracma de prata. ID: SNGuk_0101b0021. Fig.11: Siracusa; anv. cabeça laure-

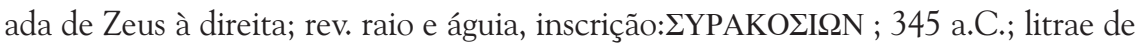
bronze. ID: SNGuk_0101a0065. Fig.12: Metaponto; anv. cabeça feminine; rev. grãode-trigo; 400-350 a.C.; óbolo de bronze. ID: SNGuk_1000_0276.

\section{FONTES MATERIAIS}

Sylloge Nummorum Graecorum ${ }^{11}$

http://www.s137585473.websitehome.co.uk/

KRAAY, C.M. Archaic and Classical Greek Coins. Londres: Methuen, 1976.

RIZZO, G. E. Larte della moneta nella Sicilia greca. Sl: Brancato Editore, 2003.

11 A Sylloge Nummorum Graecorum é um catálogo sistemático de todos os exemplares monetários existentes nas principais coleções de moedas gregas do mundo. Trata-se de uma série patrocinada pela União Acadêmica Internacional e que teve início na década de 1930. Hoje, está em parte disponível pela internet e constitui instrumento de trabalho indispensável da Numismática da Grécia antiga. 


\section{REFERÊNCIAS BibliográfICAS}

COOK, B.F. Greek Inscriptions. Berkeley; Los Angeles: University of California Press, 1987.

FLORENZANO, M.B.B. Fontes sobre a origem da moeda: apresentação crítica. Rev. do Museu de Arqueologia e Etnologia, São Paulo, 11: 201-211, 2001.

FRÈRE, H. Numismática. Uma introdução aos métodos e à classificação. São Paulo; Louvain-la-Neuve: São Paulo Editora S.A., 1984.

GAUTHIER, Ph. Légendes monétaires grecques. In: HACKENS, T., et. al. (eds.). Numismatique antique, problèmes et méthodes. Louvain-Nancy, 1975, p. 165-179.

HACKENS, T., et. al. (eds.). Numismatique antique, problèmes et méthodes. LouvainNancy, 1975.

HANSEN, H. H.; NIELSEN, T.H. (orgs.). An Inventory of Archaic and Classical Poleis. Oxford: Oxford University Press, 2005.

KRAAY, C.M. Archaic and Classical Greek Coins. Londres: Methuen, 1976.

LACROIX, L. Les types de monnaies grecques. In: HACKENS, T., et. al. (eds.). Numismatique antique, problèmes et méthodes. Louvain-Nancy, 1975, p. 153-163.

MARQUES, M.G. Introdução à numismática. Lisboa: Dom Quixote, 1982.

RIZZO, G. E. L'arte della moneta nella Sicilia greca. Sl: Brancato Editore, 2003.

SEAFORD, R. Money and the Early Greek mind. Homer, Philosophy, Tragedy. Cambridge: Cambridge University Press, 2004.

LAKY, L. A. Inscriptions on Greek coins: the Archaic and Classical periods.

ABSTRACT: This article intends to introduce the study of inscriptions on Greek coins through the varieties of monetary types of many Greek world poleis in the Archaic and Classical periods. Besides the translation and interpretation of the legends it will also be discussed the origin and function of the coins as objects of political affirmation and polis identity.

KEYWORDS: polis; epigraphy; numismatics; Archaic period; Classical period. 